\title{
Synthesis and Characterization of 2-Alkylbutadiene Polymers. I. Structural Characterization of 2-Ethyl-, 2-n-Propyl-, 2- Isopropyl-, and 2-n-Butylbutadiene Polymers
}

\author{
Ryotaro OHno, Masato KaWAKami, and Yasuyuki TANaKa \\ Tokyo Research Laboratory, Japan Synthetic Rubber Co., Ltd., \\ Ikuta, Kawasaki, Kanagawa, Japan.
}

(Received March 22, 1972)

\begin{abstract}
The isomeric structures of poly(2-ethyl-, poly(2-n-propyl-, poly(2-isopropyl-, and poly(2-n-butylbutadiene)s were investigated by means of NMR and infrared spectroscopies. The polymer samples were synthesized using various catalysts. The cis-trans isomerization of double bonds in these polymers was carried out by irradiating the polymers with a mercury lamp. Assignments of NMR signals in the spectra of these polymers were made by taking into account data about low-molecular-weight olefins and the cis-trans-isomerized poly(2-alkylbutadiene)s. The contents of cis-1,4 and trans-1,4 units were determined by using the resonance of methyl protons in the substituted alkyl group. The 3,4- unit content was determined by using the olefinic proton resonance. The advantages and limitations of the NMR method were discussed.

KEY WORDS Poly(2-ethylbutadiene) / Poly(2-n-propylbutadiene) / Poly(2-isopropylbutadiene) / Poly(2-n-butylbutadiene) / Cis-trans Isomerization / Isomeric Structure / NMR /
\end{abstract}

It is well known that butadiene and isoprene polymerize to stereospecific polymers consisting predominantly of cis-1,4, trans-1,4, or 1,2 (or 3,4 ) structures when using Ziegler-type catalysts or lithium compounds. The characterization of these isomeric structures has been investigated in detail by means of infrared, NMR and X-ray techniques.

Although it has already been reported that a number of 2-alkylbutadienes, i.e., 2-ethyl-, 2isopropyl-, 2-amyl-, gave an amorphous polymer, little attention has been paid to the isomericstructure of these polymers. ${ }^{1,2}$ Marconi, et al., investigated the structure of 2-n-propyl- ${ }^{3}$ and 2tert-butylbutadiene polymers ${ }^{4}$ obtained with a Ziegler-type catalyst by means of infrared and $\mathrm{X}$-ray method, and concluded that the amorphous poly(2-isopropylbutadiene) and the crystalline poly(2-tert-butylbutadiene) have predominantly cis-1,4 structure. In the patent literature ${ }^{5}$ it was reported that cis-1,4-poly(2-ethylbutadiene) having $97 \%$ of structural purity was obtained with a Ziegler-type catalyst. In this case, the isomericstructure was determined by infrared analysis.

For determination of the isomeric structures of polymers, however, infrared methods are not always usable due to lack of an adequate authentic sample, lack of characteristic infrared bands or non additive behavior of the characteristic infrared bands. This is the case with the isomeric structure of polyisoprene. ${ }^{6}$ On the other hand, NMR methods are available for determination of the isomeric structures of diene polymers without any authentic sample, when the resonance peaks are well separated and can be assigned.

The authors carried out the synthesis and polymerization of 2-alkylbutadienes in order to elucidate the effects of substituents on the isomeric structures, and physical and mechanical properties of polymers. In this paper, the polymerizations of 2-ethyl-, 2-n-propyl-, 2-isopropyl-, and 2-n-butylbutadienes were carried out by using various kinds of catalysts and the isomeric structures of these polymers were studied by NMR and infrared spectroscopies.

\section{EXPERIMENTAL}

Polymer Samples

Poly(2-ethyl-, poly(2-n-propyl-, poly(2-isopro- 
pyl-, and poly(2-n-butylbutadiene)s were prepared by (a) $\mathrm{TiCl}_{4}-\mathrm{Al}\left(\mathrm{C}_{2} \mathrm{H}_{5}\right)_{3}-\mathrm{BF}_{3} 2 \mathrm{C}_{6} \mathrm{H}_{5} \mathrm{OH}$, (b) $n$-butyllithium/heptane, (c) $\mathrm{VOCl}_{3}-\mathrm{Al}\left(\mathrm{C}_{2} \mathrm{H}_{5}\right)_{3}$, and (d) n-butyllithium/ethyl ether catalysts. Crude polymers were purified by reprecipitation from benzene solution with methanol.

\section{Cis-trans Isomerization}

The cis-trans isomerization of the polymers prepared by the catalysts (a) was carried out according to the procedure of Cunneen, et al. ${ }^{7}$ The starting polymers were dissolved in benzene so as to make a $5-\%$ solution and thiobenzoic acid ( $9 \%$ of the weight of polymer) was added to this solution. The solution was irradiated with a low-pressure mercury lamp for $7 \mathrm{hrs}$ under a nitrogen atmosphere. The isomerized polymers were purified by repeated reprecipitations from benzene solution with methanol.

\section{NM.R Measurements}

NMR spectra were taken with a Japan Electron Optics Laboratory JNM-4H-100 (100 MHz) spectrometer. A solution of the polymer (7-10\% by weight) was prepared in benzene- $d_{6}$ for poly(2-ethylbutadiene) and poly(2-isopropylbutadiene), in carbon tetrachloride for poly(2-npropylbutadiene), and in tetrachloroethylene for poly(2-n-butylbutadiene). Measurements were made at room temperature or at $80^{\circ} \mathrm{C}$ by using tetramethylsilane as an internal standard. The separation of overlapped peaks were done by means of a Du Pont 310 Curve Resolver on the assumption of a Lorentz function for each of the component signals.

\section{Infrared Measurements}

Infrared spectra were measured with a Japan Spectroscopic Co. DS-402G double-beam grating spectrometer. Measurements of the polarization spectra of stretched polymers were done by using a silver chloride polarizer. For this purpose, poly(2-alkylbutadiene)s prepared using the catalyst (a) were cured in very thin sheets using a standard sulfur recipe and were stretched almost to breaking point.

\section{RESULTS AND DISCUSSION}

NMR Signal Assignment for Poly(2-ethylbutadiene)

Figures 1 and 2 show $100-\mathrm{MHz}$ spectra of poly(2-ethylbutadiene) prepared by (a) $\mathrm{TiCl}_{4}-$ $\mathrm{Al}\left(\mathrm{C}_{2} \mathrm{H}_{5}\right)_{3}-\mathrm{BF}_{3} 2 \mathrm{C}_{6} \mathrm{H}_{5} \mathrm{OH}$ catalyst (Figure 1a), (b) $n$-butyllithium/heptane catalyst (Figure 1b),

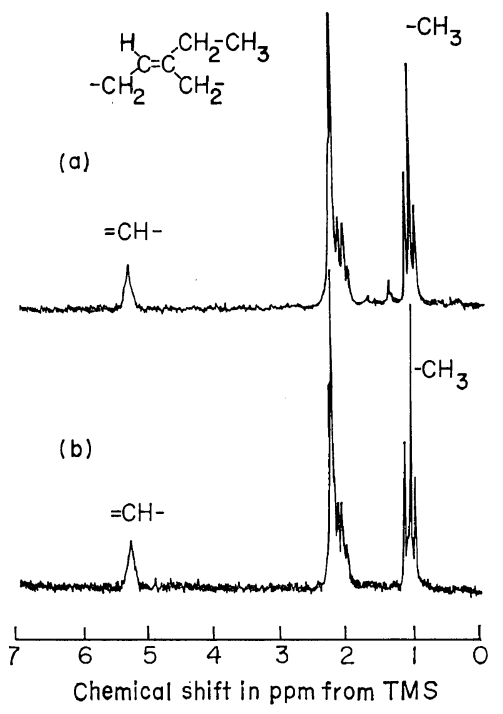

Figure 1. NMR spectra of poly(2-ethylbutadiene)s: (a) obtained by $\mathrm{TiCl}_{4}-\mathrm{Al}\left(\mathrm{C}_{2} \mathrm{H}_{5}\right)_{3}-\mathrm{BF}_{3} 2 \mathrm{C}_{6} \mathrm{H}_{5} \mathrm{OH}$ catalyst; (b) obtained by $n$-butyllithium/heptane catalyst.

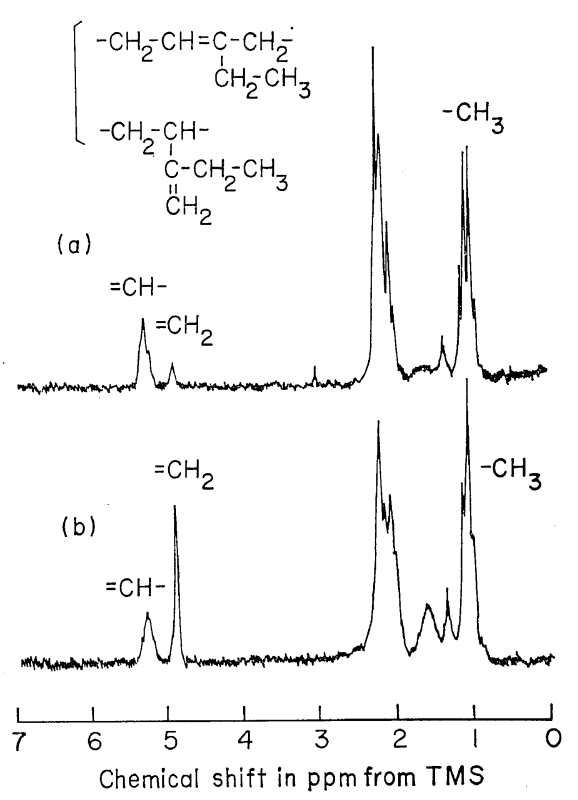

Figure 2. NMR spectra of poly(2-ethylbutadiene)s: (a) obtained by $\mathrm{VOCl}_{3}-\mathrm{Al}\left(\mathrm{C}_{2} \mathrm{H}_{5}\right)_{3}$ catalyst; (b) obtained by $n$-butyllithium/ethyl ether catalyst. 
(c) $\mathrm{VOCl}_{3}-\mathrm{Al}\left(\mathrm{C}_{2} \mathrm{H}_{5}\right)_{3}$ catalyst (Figure 2a), and (d) n-butyllithium/ethyl ether catalyst (Figure 2b). In these spectra there are three to six well-resolved peaks in two distinct groups. Peaks on the low-field side are due to the resonances of various protons directly attached to olefinic carbons. The major differences between the spectra in Figures 1 and 2 in the group of peaks located at about $1 \mathrm{ppm}$, which are presumed to be due to methyl protons in the ethyl group of the polymer. In the spectra shown in Figure 1 the methyl proton resonance is observed as a triplet centered at $1.08 \mathrm{ppm}$. On the other hand, the methyl resonance pattern of the sample prepared by the catalyst (c)

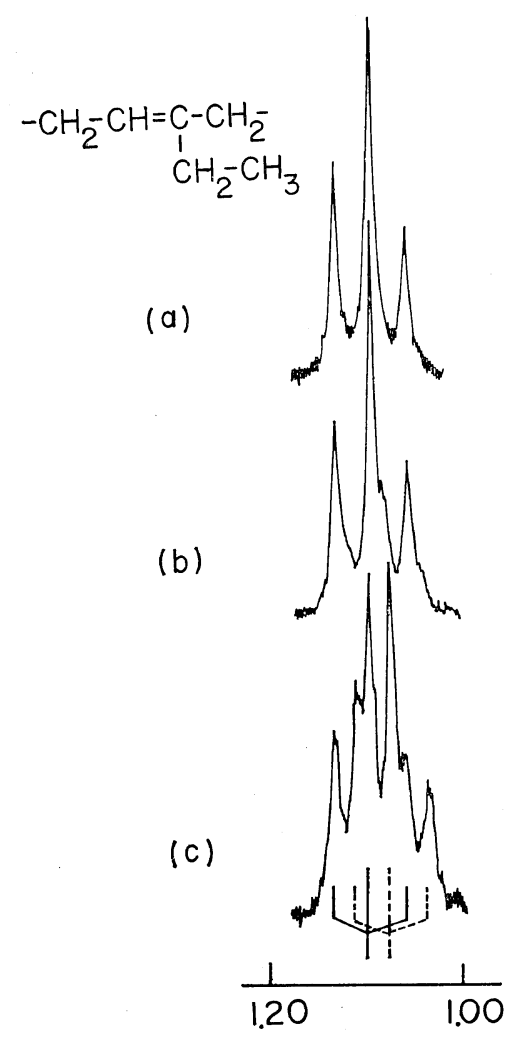

Chemical shift in ppm from TMS

Figure 3. Characteristic resonance patterns of the methyl group in poly(2-ethylbutadiene)s: (a) obtained by $\mathrm{TiCl}_{4}-\mathrm{Al}\left(\mathrm{C}_{2} \mathrm{H}_{5}\right)_{3}-\mathrm{BF}_{3} 2 \mathrm{C}_{6} \mathrm{H}_{5} \mathrm{OH}$ catalyst; (b) obtained by cis-trans isomerization of the sample (a); (c) obtained by $\mathrm{VOCl}_{3}-\mathrm{Al}\left(\mathrm{C}_{2} \mathrm{H}_{5}\right)_{3}$ catalyst; --, signals due to cis-1,4 structure; ---, signals due to trans-1,4 structure.
(Figure 2a) consists of more than three peaks. Figure 3 shows the slow sweep of this methyl resonance (Figure $3 c$ ) together with those of the polymers prepared by the catalyst (a) (Figure 3a) and by the isomerization of the sample obtained by the catalyst (a) (Figure 3b). The spectrum of the isomerized polymer exhibits small peaks as a triplet centered at $1.06 \mathrm{ppm}$. This splitting is more clearly observed in the spectrum of the sample prepared by the catalyst (c), which is presumed to consist of two triplets centered at 1.06 and $1.08 \mathrm{ppm}$. It has been reported that the methyl protons of trans olefins ${ }_{\mathrm{H}}^{\mathrm{R}}{ }_{\mathrm{C}=\mathrm{C}}>_{\mathrm{R}^{\prime}}^{\mathrm{C}-\mathrm{CH}_{3}}$ resonate at a higher field than that of cis isomers in many cases. ${ }^{8}$ On the basis of these data, it is reasonable to assume that the triplets centered at 1.06 and $1.08 \mathrm{ppm}$ can be assigned to the resonances of methyl protons in trans-1,4 and $c i s-1,4$ structural units, respectively.

In the case of the sample prepared by the catalyst (d), the resonance pattern of the methyl protons was not well-resolved (Figure $2 b$ ). This may be due to the presence of the methyl proton resonance of 3,4-structural unit at $1.10 \mathrm{ppm}$. The methyl proton resonance of 3,4 unit was read from the slow-sweep spectrum of this polymer.

The olefinic proton resonances of 1,4 and 3,4 units were observed on the low field of the spectra (Figures 1 and 2). By taking into account the data on low-molecular-weight olefins $^{8,9}$, the peaks at 5.34 and $4.97 \mathrm{ppm}$ were assigned to the resonance of $=\mathrm{CH}$ proton in the 1,4-structural unit and that of $=\mathrm{CH}_{2}$ proton in the 3,4-structural unit, respectively. These assignments are quite consistent with those of the olefinic protons of 1,4- and 3,4-polyisoprene. ${ }^{6}$ From these data, the detailed assignments of the peaks are obtained as given in the first line of Table I.

The content of 1,2 unit in these samples was considered to be negligible because of the absence of the olefinic proton resonance $-\mathrm{CH}=\mathrm{CH}_{2}$, as well as of the absence of the characteristic infrared band at $909 \mathrm{~cm}^{-1}$.

From the above assignments, it is clear that the polymers prepared by the catalysts (a) and 
R. OHNo, M. KaKawami, and Y. TANAKA

Table I. NMR assignments for poly(2-alkylbutadiene)s. ${ }^{a}$

\begin{tabular}{|c|c|c|c|c|c|c|}
\hline \multirow{2}{*}{$\begin{array}{l}\text { Alkyl } \\
\text { group }\end{array}$} & \multirow{2}{*}{ Solvent } & \multicolumn{5}{|c|}{ Chemical shift $\delta(\mathrm{ppm})$} \\
\hline & & $1,4-\mathrm{CH}=$ & $3,4=\mathrm{CH}_{2}$ & $c i s-1,4-\mathrm{CH}_{3}$ & trans-1,4 $-\mathrm{CH}_{3}$ & $3,4-\mathrm{CH}_{3}$ \\
\hline Ethyl & $C_{6} D_{6}$ & 5.34 & 4.97 & 1.08 & 1.06 & 1.10 \\
\hline n-Propyl & $\mathrm{CCl}_{4}$ & 5.12 & 4.74 & 0.87 & 0.90 & 0.93 \\
\hline Isopropyl & $\mathrm{C}_{6} \mathrm{D}_{6}$ & 5.40 & 4.96 & 1.13 & 1.10 & 1.15 \\
\hline$n$-Butyl & $\mathrm{C}_{2} \mathrm{Cl}_{4}$ & 5.15 & 4.77 & 0.90 & 0.88 & 0.92 \\
\hline a 1,4 Structu & $\mathrm{re},-\mathrm{CH}_{2}$ & $\begin{array}{c}\mathrm{H}=\underset{\mid}{\mathrm{C}}-\mathrm{CH}_{2} \\
\left(\mathrm{CH}_{2}\right)_{n} \\
{ }_{\mathrm{C}} \\
\mathrm{CH}_{3}\end{array}$ & 3,4 Structu & $\begin{array}{c}-\mathrm{CH}_{2}-\mathrm{CH}- \\
\stackrel{\mathrm{C}}{\mathrm{U}}-\mathrm{C} \\
\mathrm{CH}_{2}\end{array}$ & ${ }_{n}-\mathrm{CH}_{3}$ & \\
\hline
\end{tabular}

(b) are predominantly composed of cis-1,4 units. However, as is shown in Figure 1a, an additional small peak can be observed at about $1.3 \mathrm{ppm}$. Since the relative intensity of this peak did not change with repeated precipitation of the sample, the possibility of an impurity remaining may be ruled out. It was reported that cyclized 1,4-polyisoprenes exhibit broad peaks at around 0.9 and $1.6 \mathrm{ppm}^{10}$. This strongly suggests that small parts of the polymer

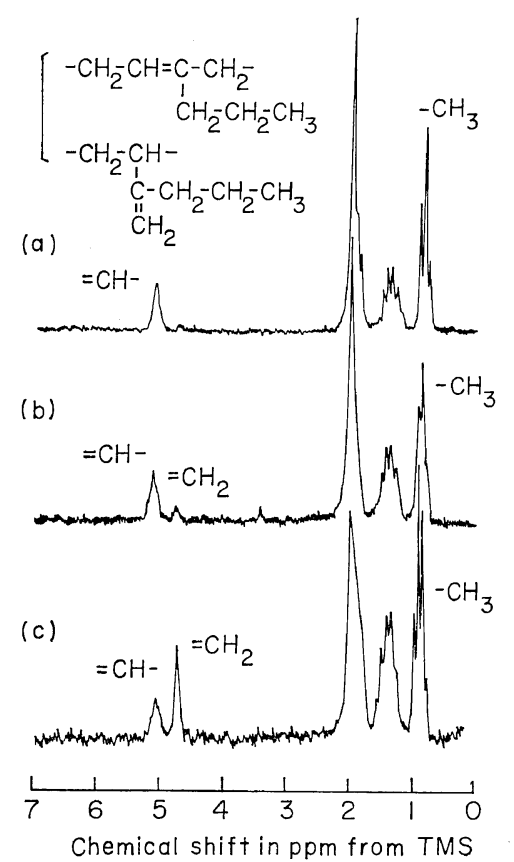

Figure 4. NMR spectra of poly(2-n-propylbutadiene)s: (a) obtained by $\mathrm{TiCl}_{4}-\mathrm{Al}\left(\mathrm{C}_{2} \mathrm{H}_{5}\right)_{3}-$ $\mathrm{BF}_{3} 2 \mathrm{C}_{6} \mathrm{H}_{5} \mathrm{OH}$ catalyst; (b) obtained by $\mathrm{VOCl}_{3}$ $\mathrm{Al}\left(\mathrm{C}_{2} \mathrm{H}_{5}\right)_{3}$ catalyst; (c) obtained by $n$-butyllithium/ ethyl ether catalyst. chain have been isomerized to a cyclic structure in the course of polymerization by the catalyst (a).

NMR Signal Assignments for Poly(2-n-propyl-, Poly(2-isopropyl-, and Poly(2-n-butylbatadiene)s

Figures 4, 6, and 8 show $100-\mathrm{MHz}$ spectra of poly(2-n-propyl-, poly(2-isopropyl-, and poly(2-nbutylbutadiene)s, respectively. As in the case

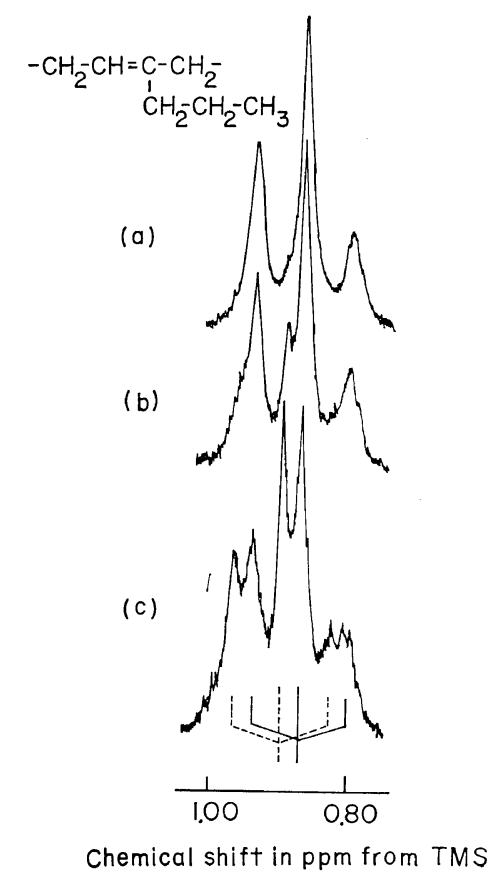

Figure 5. Characteristic resonance patterns of the methyl group in poly(2-n-propylbutadiene)s: (a) obtained by $\mathrm{TiCl}_{4}-\mathrm{Al}\left(\mathrm{C}_{2} \mathrm{H}_{5}\right)_{3}-\mathrm{BF}_{3} 2 \mathrm{C}_{6} \mathrm{H}_{5} \mathrm{OH}$ catalyst; (b) obtained by cis-trans isomerization of the sample (a); (c) obtained by $\mathrm{VOCl}_{3}-\mathrm{Al}\left(\mathrm{C}_{2} \mathrm{H}_{5}\right)_{3}$ catalyst; - , signals due to cis-1,4 structure; --.-, signals due to trans-1,4 structure. 
Characterization of 2-Alkylbutadiene polymers

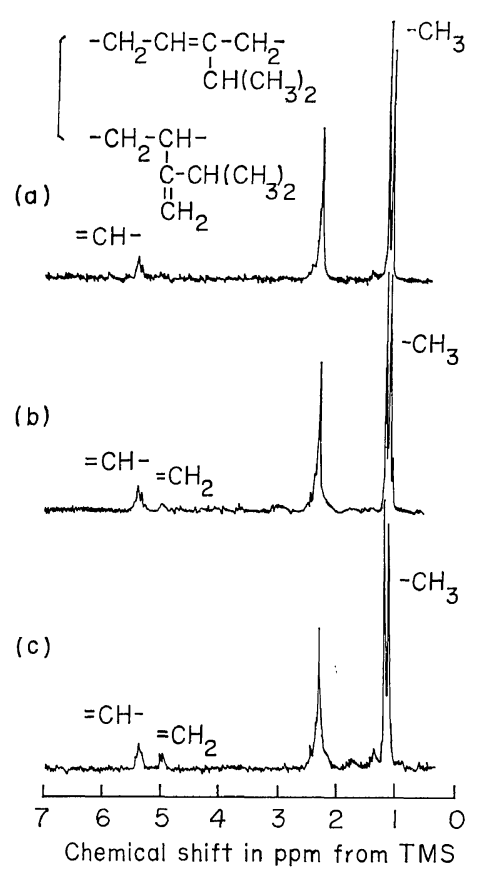

Figure 6. NMR spectra of poly(2-isopropylbutadiene)s: (a) obtained by $\mathrm{TiCl}_{4}-\mathrm{Al}\left(\mathrm{C}_{2} \mathrm{H}_{5}\right)_{3}-\mathrm{BF}_{3}-$ $2 \mathrm{C}_{6} \mathrm{H}_{5} \mathrm{OH}$ catalyst; (b) obtained by $\mathrm{VOCl}_{3}-$ $\mathrm{Al}\left(\mathrm{C}_{2} \mathrm{H}_{5}\right)_{3}$ catalyst; (c) obtained by $n$-butyllithium/ ethyl ether catalyst.

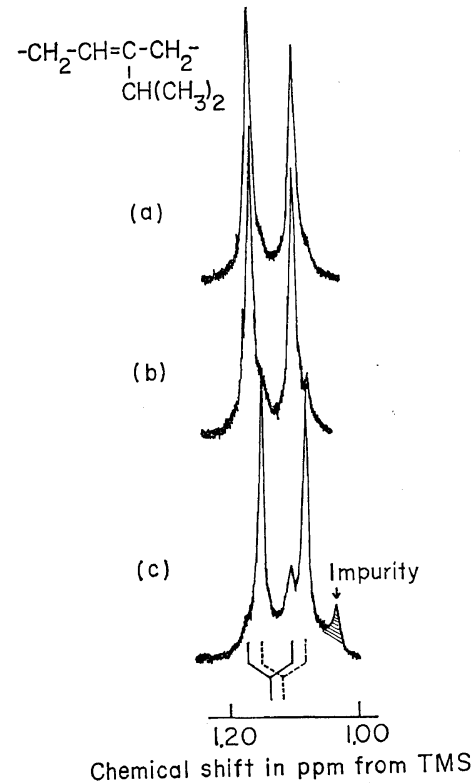

Figure 7. Characteristic resonance patterns of the methyl group in poly(2-isopropylbutadiene)s: (a) obtained by $\mathrm{TiCl}_{4}-\mathrm{Al}\left(\mathrm{C}_{2} \mathrm{H}_{5}\right)_{3}-\mathrm{BF}_{3} 2 \mathrm{C}_{6} \mathrm{H}_{5} \mathrm{OH}$ catalyst; (b) obtained by cis-trans isomerization of the sample (a); (c) obtained by $\operatorname{VOCl}_{3}-\mathrm{Al}\left(\mathrm{C}_{2} \mathrm{H}_{5}\right)_{3}$ catalyst; -, signals due to cis-1,4 structure; ----, signals due to trans-1,4 structure.

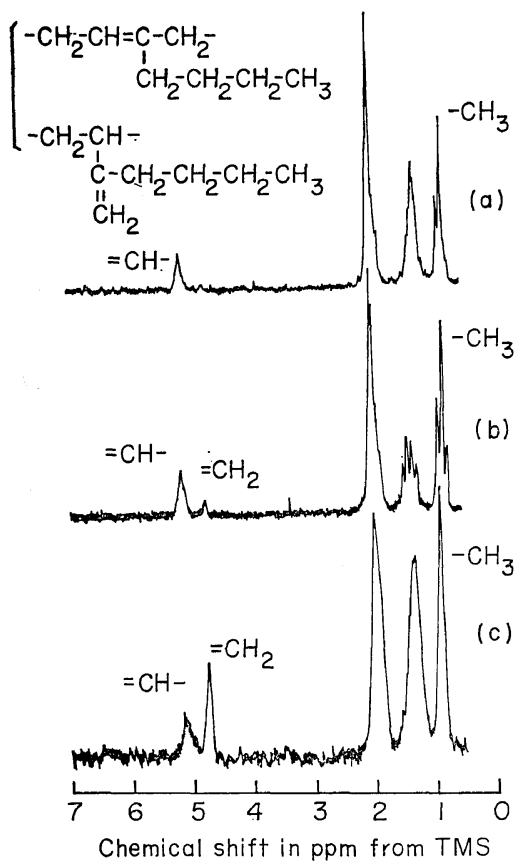

Figure 8. NMR spectra of poly(2-n-butylbutadiene)s: (a) obtained by $\mathrm{TiCl}_{4}-\mathrm{Al}\left(\mathrm{C}_{2} \mathrm{H}_{5}\right)_{3}-$ $\mathrm{BF}_{3} 2 \mathrm{C}_{6} \mathrm{H}_{5} \mathrm{OH}$ catalyst; (b) obtained by $\mathrm{VOCl}_{3}-$ $\mathrm{Al}\left(\mathrm{C}_{2} \mathrm{H}_{5}\right)_{3}$ catalyst; (c) obtained by $n$-butyllithium/ ethyl ether catalyst.

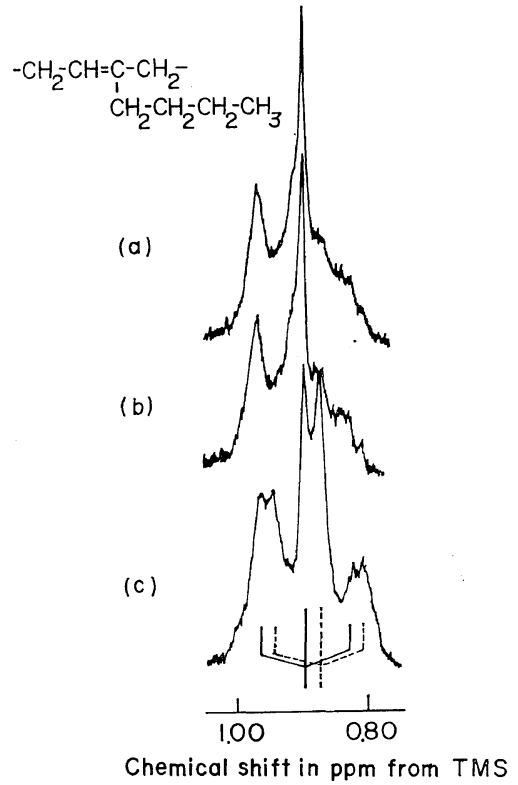

Figure 9. Characteristic resonance patterns of the methyl group in poly(2-n-butylbutadiene)s: (a) obtained by $\mathrm{TiCl}_{4}-\mathrm{Al}\left(\mathrm{C}_{2} \mathrm{H}_{5}\right)_{3}-\mathrm{BF}_{3} 2 \mathrm{C}_{6} \mathrm{H}_{5} \mathrm{OH}$ catalyst; (b) obtained by cis-trans isomerization of the sample (a); (c) obtained by $\operatorname{VOCl}_{3}-\mathrm{Al}\left(\mathrm{C}_{2} \mathrm{H}_{5}\right)_{3}$ catalyst; - , signals due to cis-1,4 structure; ----, signals due to trans-1,4 structure. 
of poly(2-ethylbutadiene), the main differences between the spectra can be observed in the methyl proton resonance located at about $1 \mathrm{ppm}$ for each of the polymers. Figures 5, 7, and 9 show the slow sweeps of the methyl resonances of poly(2-n-propyl-, poly(2-isopropyl-, and poly(2-nbutylbutadiene)s, respectively. In these Figures, the differences between the resonances of cis-1,4 and trans-1,4 methyl protons can be clearly observed in the spectra of the samples prepared by the catalysts (a) and (c), and of the sample obtained by the isomerization of the sample prepared by the catalyst (a). Assignments of the peaks were made by taking into account the data on low-molecular-weight olefins. ${ }^{8}$ These assignments are listed in Table I. The trans-1,4 methyl protons are observed at higher fields than cis-1,4 methyl protons only in poly(2-npropylbutadiene). This is probably due to the difference of the geometrical relation between the double bonds and the methyl groups in poly(2-n-propylbutadiene) and other polymers.

\section{Determination of Isomeric Structure}

On the basis of the assignments, the content of the isomeric-structural units in poly(2-ethyl-, poly(2-n-propyl-, poly(2-isopropyl-, and poly(2-nbutylbutadiene)s can be determined. As an example, the content of 3,4 unit in poly(2ethylbutadiene) can be calculated by the following equations.

$$
\begin{aligned}
& {[\text { cis- } 1,4]+[\text { trans }-1,4]+[3,4]=1} \\
& I(5.34) / I(4.97)=2([\text { cis }-1,4]+[\text { trans }-1,4]) /[3,4] \\
& I(1.08-1.10) / I(1.06)=([\text { cis }-1,4] \\
& \quad+[3,4]) /[\text { trans }-1,4]
\end{aligned}
$$

Here, the bracket denotes the mole fraction of the respective structural unit indicated and $I(\delta)$ represents the relative intensity of the peak at the chemical shift $\delta$.

In order to improve the accuracy of measurements, the overlapped methyl resonance pattern was separated into its components using a curve fitting method with a Du Pont 310 Curve Resolver. Figure 10 shows an example of the curve fitting. When the content of 3,4 unit is higher than about $20 \%$, the broad unresolved methyl resonance peak cannot be unequivocally separated, and hence, only the content of 3,4 and total 1,4-units were determined.

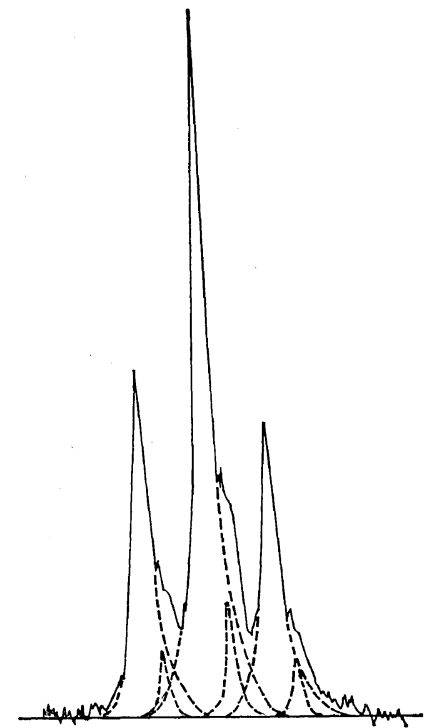

Figure 10. The separation method for the overlapped methyl resonance pattern using a curve fitting technique with the cis-trans-isomerized poly(2-ethylbutadiene).

In a similar manner as above, the contents of cis $-1,4$ trans $-1,4$, and 3,4, units of the other poly(2-alkylbutadiene)s can be determined.

\section{Infrared Spectra of Poly(2-alkylbutadiene)s}

Figure 11 shows the infrared spectra of poly(2-ethylbutadiene)s prepared by the catalysts (a) and (c). The absorption bands of these samples show a striking resemblance to those of polyisoprenes prepared by the same catalysts. The absorption bands at $840 \mathrm{~cm}^{-1}$ in Figure 11a are very similar to those of polyisoprene. The polarization spectrum of the cis-1,4 poly(2-ethylbutadiene) shows that the $840-\mathrm{cm}^{-1}$ band is perpendicularly polarized with respect to the direction of stretching. This indicates that the $840-\mathrm{cm}^{-1}$ band can be attributed to the same origin as polyisoprene, which has been recognized to be due to the $\mathrm{CH}$ out-of-plane vibration of the $-\mathrm{C}\left(\mathrm{CH}_{3}\right)=\mathrm{CH}-$ group of both cis-1,4 and trans-1,4 structures. ${ }^{11}$ The intensity of the absorption band at $890 \mathrm{~cm}^{-1}$ was directly proportional to the content of 3,4 unit determined by the NMR measurements. This indicates that the $890-\mathrm{cm}^{-1}$ band is due to the $\mathrm{CH}_{2}$ vibration of the $\mathrm{CH}_{2}=\mathrm{C}\left(\mathrm{CH}_{3}\right)$ - group.

The infrared spectra of the other poly(2-alkyl- 


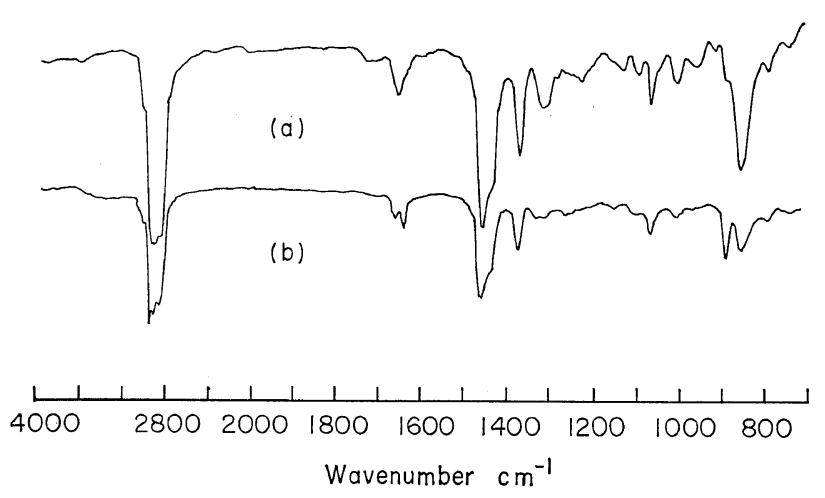

Figure 11. Infrared spectra of poly(2-ethylbutadiene)s: (a) obtained by $\mathrm{TiCl}_{4}-\mathrm{Al}\left(\mathrm{C}_{2} \mathrm{H}_{5}\right)_{3}-\mathrm{BF}_{3} 2 \mathrm{C}_{6} \mathrm{H}_{5} \mathrm{OH}$ catalyst; (b) obtained by $\operatorname{VOCl}_{3}-\mathrm{Al}\left(\mathrm{C}_{2} \mathrm{H}_{5}\right)_{3}$ catalyst.

butadiene)s were much the same and the content of 1,2 unit in these polymers was confirmed as negligible by the absence of the characteristic infrared band at $909 \mathrm{~cm}^{-1}$.

The spectrum of the isomerized poly(2-ethylbutadiene) was identical to that of the original cis-1,4 poly(2-ethylbutadiene). Thus, as in the case of polyisoprene, the geometric isomers of poly(2-ethylbutadiene) cannot be distinguished using only the appearance of the absorption bands. Therefore, it may be concluded that the NMR method described here has several advantages over infrared procedures for the determination of cis-1,4 and trans-1,4 contents in poly(2-alkylbutadiene)s.

\section{REFERENCES}

1. C. S. Marvel, J. L. R. Williams, and H. E. Baumgarten, J. Polym. Sci., 4, 583 (1949).
2. C. G. Overberger, L. H. Arond, R. H. Wiley and R. G. Garret, ibid., 7, 431 (1951).

3. W. Marconi, A. Mazzei, S. Cucinella, M. Cesari, and E. Pauluzzei, ibid., Part A, 3, 123 (1965).

4. W. Marconi, A. Mazzei, S. Cucinella, and M. Cesari, ibid., Part A, 2, 4261 (1964).

5. Goodyear Tire \& Rubber Co., British Patent 1004665 (1965).

6. Y. Tanaka, Y. Takeuchi, M. Kobayashi, and H. Tadokoro, J. Polym. Sci., Part A-2, 9, 43 (1971).

7. J. I. Cunneen, G. M. C. Higgins, and W. F. Watson, ibid., 40, 1 (1959).

8. F. C. Stehling and K. W. Bartz, Anal. Chem., 38, 1469 (1966).

9. H. Y. Chen, ibid., 34, 1134 (1962).

10. M. A. Golub and J. Heller, Tetrahedron Letter, 1963, 2137.

11. J. L. Binder, J. Polym. Sci., Part A, 1, 37 (1963). 